PIs: Professors E. James Davis and Barbara Krieger-Brockett

STUDENTS: Theresa M. Allen, Ph.D. Candidate in Chemical Engineering (part support) Scot D. Rassat, Ph.D. Candidate in Chemical Engineering Warguang Li, M.S. Candidate in Chemical Engineering

INSTITUTION: Department of Chemical Engineering, BF-10 University of Washington

Seattle, WA 98195

(206) 543-2250 and FAX 2065433778

$\mathrm{DOE} / \mathrm{PC} / 89790--8$

GRANT NO.: DE-F $322-89 P C 89790$

PERIOD OF PERFORMANCE: 1 July, 1991 to 31 September 1991

\title{
BACKGR.OUND
}

The objective of this research is to develop and apply novel single microparticle techniques to perform simultaneously thermogravimetric analysis and Raman/fluorescence spectroscopies on microparticles of coal (macerals) and sorbents $(\mathrm{CaO})$ used for coal desulfurization. The combination electrodynamic balance/spectrometer system is being used to chemically characterize macerals from different ranks of coal and to explore the chemistry and chemical reaction rates associated with processes involving such microparticles. Rate processes will be examined at elevated temperatures by heating the particles electromagnetically, and a significant part of the research involves the design, construction and utilization of a microparticle heating system.

\section{WORK COMPLETED}

Work bas continued on the hardware and software related to the infrared particle heating system and the feedback controller needed for temperature and heating rate control. An extensive study of the chemical reaction between levitated $\mathrm{CaO}$ particles and a humid $\mathrm{SO}_{2}$ /air stream at ambient temperatures was completed, and a paper based on this study was submitted for publication.

The reaction between $\mathrm{SO}_{2}$ and the sorbent $\mathrm{CaO}$ was followed by recording Raman spectra of the electrodynamically levitated microparticle as the reaction proceeded. At ambient temperatures no reaction was detected in the absence of water vapor, but in the presence of a humid gas stream a two-stage reaction was observed. Initially, the hygroscopic $\mathrm{CaO}$ particle absorbed water as indicated by an increase in mass. Figure 1 shows the increase in levitation voltage, which is directly proportional to the particle mass, for four different particles. Two of the particles were exposed to humid air alone and two were levitated in a stream containing $\mathrm{SO}_{2}$. We note that the curves tend to approach an asymptotic limit of approximately a $50 \%$ mass increase.

Raman spectra obtained during the experiment show the formation of $\mathrm{Ca}(\mathrm{OH})_{2}$ as the absorbed water reacts with $\mathrm{CaO}$. Figure 2 displays the increase in the Raman peak associated with the hydroxyl stretching mode of $\mathrm{Ca}(\mathrm{OH})_{2}$ for (a) a $60 \mu \mathrm{m}$ particle calibration particle of $\mathrm{Ca}(\mathrm{OH})_{2}$ and for (b) a $100 \mu \mathrm{m}$ reacting particle of $\mathrm{CaO}$ levitated in a humid stream of $\mathrm{SO}_{2} \mathrm{~N}_{2}$. The formation of the hydroxide is clearly demonstrated in this figure. If the chemical reaction between $\mathrm{CaO}$ and $\mathrm{H}_{2} \mathrm{O}$ went to completion, the mass increase would be $32.11 \%$. Thus, Figure 1 indicates that there is excess water taken up in the pores of the particle.

DISTRIBUTIONN OF THIS DOCUMENT IS UNLMITED -1 - 


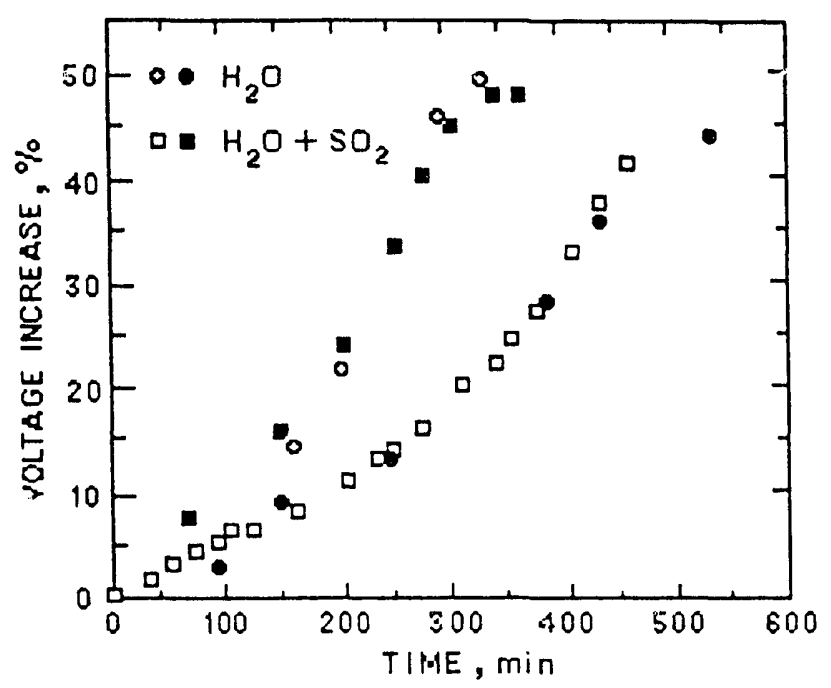

Figure 1. The mass increase of levitated $\mathrm{CaO}$ particles with and without $\mathrm{SO}_{2}$ in the gas stream flowing past the particle.

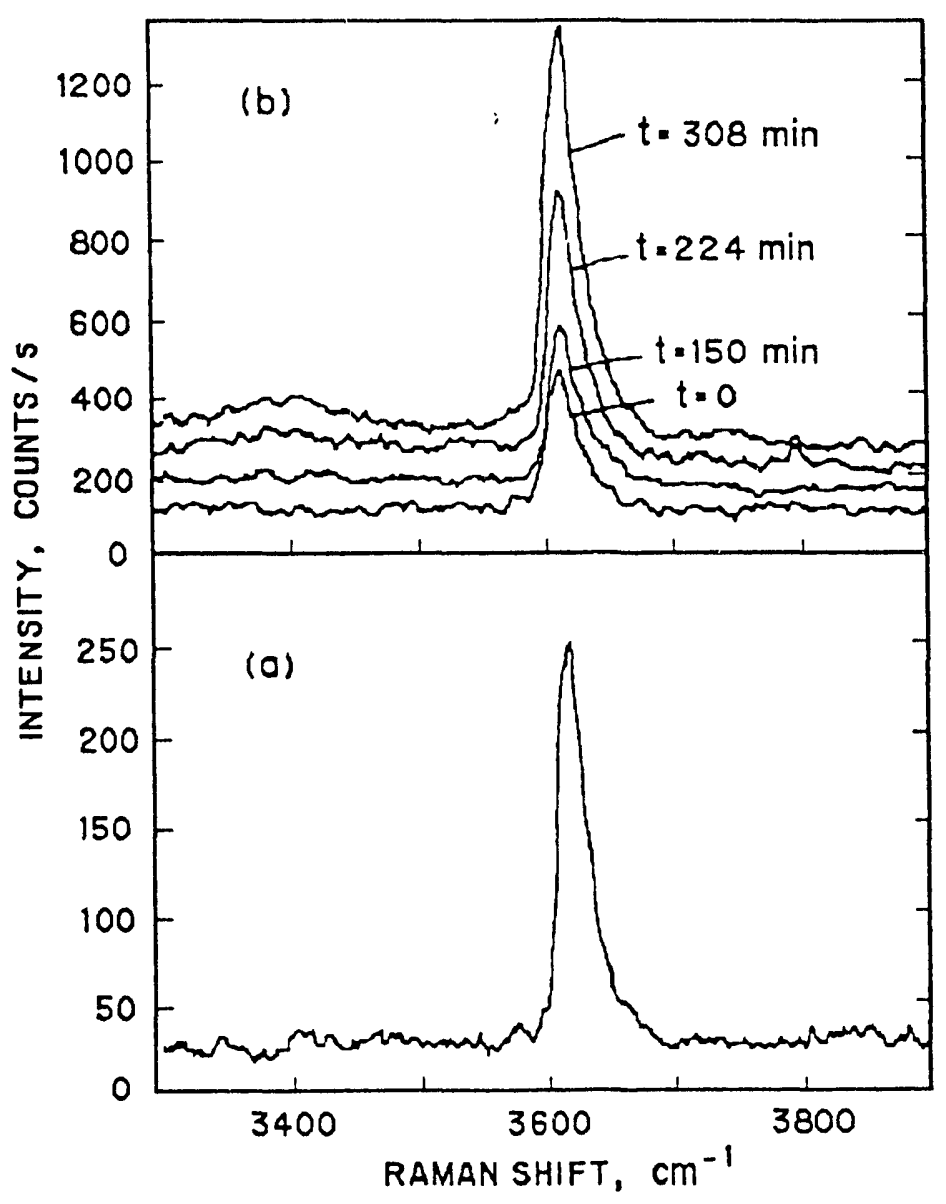

Figure 2. A comparison between the Raman spectrum for the hydroxyl stretching mode of (a) a $60 \mu \mathrm{m}$ reference particle of $\mathrm{Ca}(\mathrm{OH})_{2}$ and (b) a $100 \mu \mathrm{m}$ particle of $\mathrm{CaO}$ reacting with water vapor and $\mathrm{SO}_{2}$. 
The Raman spectra show that the formation of $\mathrm{Ca}(\mathrm{OH})_{2}$ is followed by reaction with $\mathrm{SO}_{2}$ to form $\mathrm{CaSO}_{3} \cdot \mathrm{nH}_{2} \mathrm{O}$, where $\mathrm{n}=1 / 2$. It is known that at elevated temperatures $\mathrm{CaSO}_{4}$ is formed by the reaction between $\mathrm{CaO}$ and $\mathrm{SO}_{2}$, and it is clear from our study that the lowtemperature reaction proceeds via the formation of $\mathrm{Ca}(\mathrm{OH})_{2}$.

Raman spectra obtained at various times during the reaction are presented in Figure 3 and show the formation of the hemihydrate of $\mathrm{CaSO}_{3}$. If the reaction between the original $\mathrm{CaO}$ had gone to completion to form the hemihydrate of $\mathrm{CaSO} 3$, the mass increase would be $130.3 \%$. Thus, the mass increases indicated by Figure 1 indicate that complete reaction of $\mathrm{CaO}$ did not occur. It is likely that pore-plugging occurred, and this prevented $\mathrm{SO}_{2}$ from reaching unreacted $\mathrm{CaO}$ within the particle.

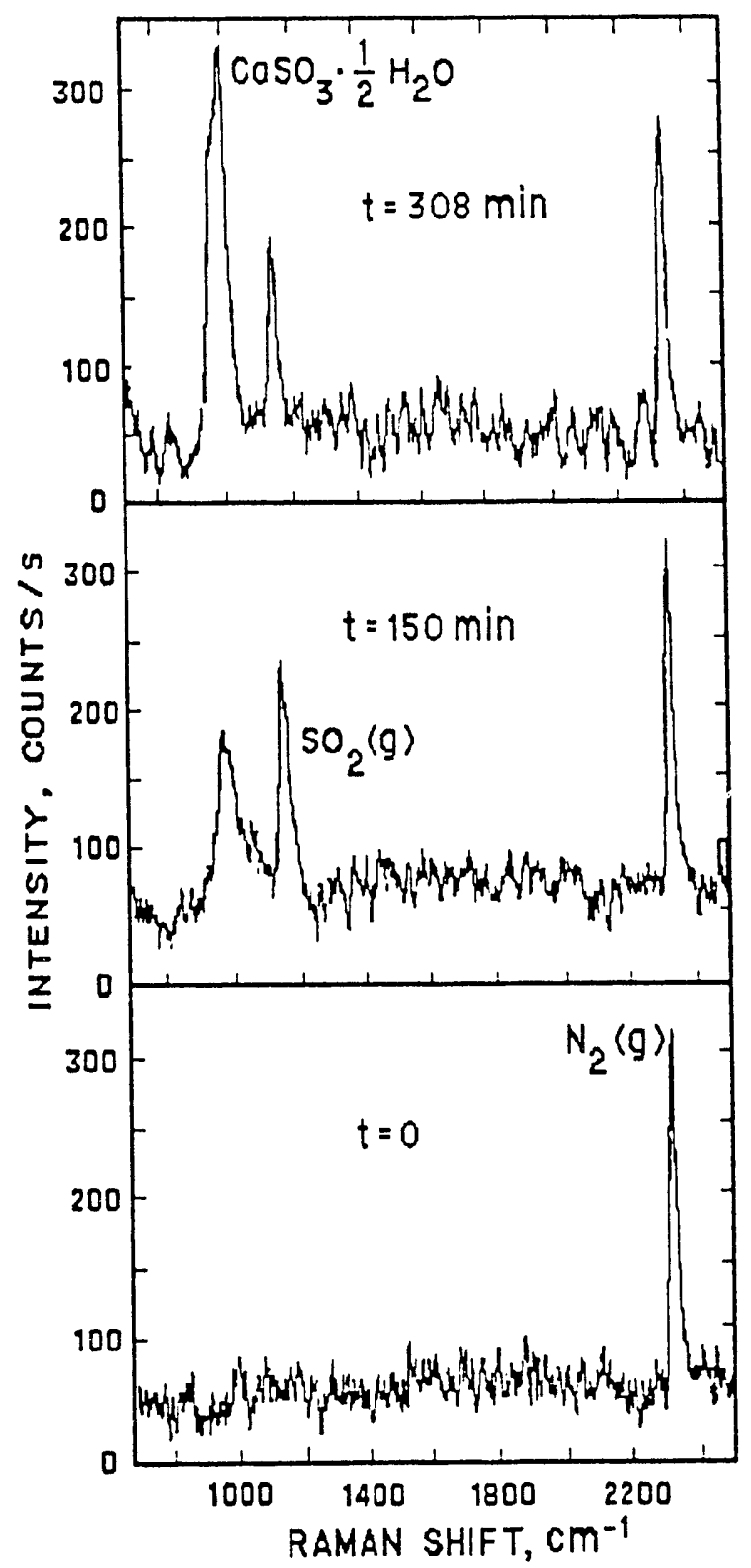

Figure 3. Raman spectra showing the formation of $\mathrm{CaSO}_{3} \cdot \mathrm{nH}_{2} \mathrm{O}$ for $\mathrm{n}=1 / 2$ as the reaction proceeds between a $\mathrm{CaO}$ particle and a humid stream of $\mathrm{SO}_{2} / \mathrm{N}_{2}$. The peaks corresponding to gas phase $\mathrm{SO}_{2}$ and $\mathrm{N}_{2}$ are also labeled. 


\section{PLANS FOR THE NEXT OUARTER}

Completion of the construction and testing of the particle heating system and its feedback control apparatus is anticipated. Spectroscopic measurements of macerals will be extended to higher temperatures as the particle heating system is tested. Sorbent/SO2 reactions will also be examined at elevated temperatures.

\section{PUBLICATIONS DURING THIS QUARTER}

Rassat, S. D., and Davis, E. J., "Chemical Reaction of Sulfur Dioxide with a Calcium Oxide Aerosol Particle," submitted to J. Aerosol Sci. .

Buehier, M. F., Allen, T. M., and Davis, E. J., "Microparticle Raman Spectroscopy of Multicomponent Aerosols," J. Colloid Interface Sci. 146, 79-89 (1991). 
